\title{
Evaluation of biofilm formation on acrylic resin surfaces coated with silicon dioxide: an in situ study
}

Rossano Vinícius Dala Rosa SILVA(a) Isabele Carrilho JARROS(b) (iD Altair Antoninha DEL BEL CURY(c) Sharanbir Kaur SIDHU(d) (D) Sónia SILVA(e) Melyssa Fernanda Norman NEGR(b) (1) Renata Corrêa PASCOTTO(a)

(a) Universidade Estadual de Maringá - UEM, Department of Dentistry, Maringá, PR, Brazil.

(b)Universidade Estadual de Maringá - UEM, Division of Medical Mycology, Department of Clinical Analysis, Maringá, Paraná, Brazil.

(c) Universidade Estadual de Campinas - Unicamp, Piracicaba Dental School, Department of Prosthodontics and Periodontology, Piracicaba, SP, Brazil.

(d) Queen Mary University, Barts \& The London School of Medicine and Dentistry, Centre for Oral Bioengineering, London, UK.

(e) University of Minho, Centre of Biological Engineering, Laboratório de Investigação Rosário Oliveira, Braga, Portugal.

Declaration of Interests: The authors certify that they have no commercial or associative interest that represents a conflict of interest in connection with the manuscript.

Corresponding Author:

Renata Corrêa Pascotto

E-mail: renatapascotto@gmail.com

hitps://doi.org/10.1590/1807-3107bor-2022.vol36.0007

Submitted: February 17, 2021

Accepted for publication: July 5, 2021

Last revision: September 14, 2021
Abstract: Biofilm on acrylic resin dental prostheses may cause gingival inflammation. This study evaluated the influence of a silicon dioxide coating layer applied onto acrylic resin on the adhesion of microorganisms. Blocks (5 $5 \times 3 \mathrm{~mm})$ of acrylic resin were evaluated for surface roughness and divided into two groups: control (CG) and coated with silicon dioxide (LG group). The specimens were evaluated by scanning electron microscopy $(\mathrm{n}=1)$ and by contact angle analysis $(\mathrm{n}=3)$. For the in situ study, 20 volunteers wore acrylic palatal devices containing three samples from each group $(n=60)$ for 2 days. The biofilm formed was quantified by metabolic activity and total biomass using the crystal violet assay. The results were subjected to Bartlett's normality test and Gamma model with random effect for the response variable $(\alpha=5 \%$ ). The mean contact angle of the coated group was significantly lower than that of the uncoated group $(\mathrm{p}<0.05)$. The metabolic activity of microorganisms in the biofilm on the blocks treated with coating was significantly lower than that of control blocks $(p=0.02)$. Regarding the amount of extracellular matrix produced by the microorganisms, there was no difference between the CG and LG group $(p=0.05)$. The application of a silicon dioxide coating on acrylic resin reduced the activity of the polymicrobial biofilm formed in situ. This coating may be advantageous for patients with conventional complete dentures or implants made of acrylic resin and who have motor difficulties that prevent them from cleaning their prostheses properly.

Keywords: Silicon Dioxide; Acrylic Resins; Cell Adhesion; Biofilms; Biomass.

\section{Introduction}

In the last National Oral Health Survey ${ }^{1}$ in Brazil carried out in 2010, despite a significant decrease in the rate of dental caries in different age groups and an increase in access to health services, the population continues to lose teeth throughout life ${ }^{1}$. It is estimated that the need for a prosthesis occurs in $68.8 \%$ of adult patients. ${ }^{2}$ Among older patients, aged 65 to 74 years, only $23.5 \%$ did not wear maxillary prostheses. ${ }^{2}$ Studies carried out in Europe concluded that approximately one third of older people in Finland, Greece, Turkey, and Bulgaria edentulous. ${ }^{2}$ Several other 
European countries have approximately $20 \%$ of their population with the same problem. ${ }^{2}$

Acrylic resin has been widely used as a denture base since 1937, thanks to characteristics such as low cost, easy handling, and color matching ability. ${ }^{3,4}$ However, over time, this material retains pigments and microorganisms, leading to biofilm formation, which can cause bad breath and gingival inflammation. An effective method for reducing microbial adhesion and pigment retention in the surface porosities of acrylic resin has not yet been discovered., 3 Various cleaning methods have been used for disinfection ${ }^{6,7,8}$ or structural alteration, allowing the development of resins with antimicrobial properties. ${ }^{910}$ Despite helping to decrease microbial biofilm on surfaces, these methods can negatively alter the physical and mechanical properties of the resin, ${ }^{6,9}$ influencing its aesthetics and durability. In addition, a degree of coordination and manual dexterity is required for the cleaning to be effective. Older patients often lose the motor capacity required for the cleaning procedure. ${ }^{7}$

A waterproof and smooth surface is of great importance in preventing biofilm retention. ${ }^{11} \mathrm{~A}$ set of applications of silicon dioxide coating was established in a German patent filed in 2007. ${ }^{12}$ Nanoscale silicon dioxide has been used in hospital environments. ${ }^{13}$ Silicon dioxide coating results in a surface with a massively reduced amount of microorganisms and is easy to clean. In addition, silicon dioxide has been shown to be effective in reducing the adhesion of C. albicans to acrylic resin surfaces ${ }^{14,15,16}$ and a recent in vivo study has demonstrated a high level of tissue biocompatibility of acrylic resin coated with silicon dioxide with low deleterious risk to patients. ${ }^{17}$ Currently, it is possible to find it in the form of spray-on liquid glass, so it can be used easily in clinics.

The null hypothesis was that as silicon dioxide would act as a polymicrobial biofilm inhibitor on acrylic resin as it is indicated as a potential surface coating agent.

\section{Methodology}

This project was approved by the Local Ethics Committee (CAAE: 86984317.9.0000.0104, process number 2.698.664)

\section{Study design}

The influence of a silicon dioxide coating layer applied onto acrylic resin on the adhesion of microorganisms was evaluated in situ in 20 volunteers who wore a palatal device containing three samples in each of two groups (control and experimental).

\section{Preparation of the specimens}

One hundred and twenty $5 \times 5 \times 3 \mathrm{~mm}$ block specimens of thermosetting acrylic resin were produced (VipiCril Plus, VIPI Indústria Pirassununga, Brazil) . Thermopolymerizable acrylic liquid (PALATON, Dencril Odontological Products, Pirassununga, Brazil) was mixed in a container with acrylic resin powder (VipiCril Plus, VIPI Indústria Pirassununga, Brazil), according to the proportions indicated by the manufacturer $(6.5 \mathrm{~mL}$ of liquid for $14 \mathrm{~g}$ of powder). After entering the plastic phase, the material was pressed and placed in a thermo pneumatic polymerizer at a temperature of $80^{\circ} \mathrm{C}$ and 100 pounds of pressure for $10 \mathrm{~min}$. The specimens were finished manually with drills and cutters, thereby standardizing their dimensions.

\section{Surface roughness}

Considering the need for surface roughness standardization, the acrylic resin blocks were subjected to sequential polishing, initially with \# 320-, 400-, and 600-grit silicon carbide discs on a polishing machine (Aropol -2V, Arotec SA Ind. and Com., Cotia, Brazil) for $15 \mathrm{~s}$ and then with felt (Arotec SA Ind. and Com., Cotia, SP, Brazil) and diamond pastes $(6 \mu \mathrm{m}$, $3 \mu \mathrm{m}$, and $1 \mu \mathrm{m}$, -Arotec SA Ind. and Com., Cotia, Brazil). Between each step and after finishing and polishing, the specimens were cleaned and washed with distilled water in an ultrasonic bath for $2 \mathrm{~min}$, (Biowash STD-Bioart, São Paulo, Brazil) to remove debris from the surface.

The surface roughness $(\mu \mathrm{m})$ of the specimens was then measured using a profilometer (Surfcorder SE 1700; Kosaka Laboratory Ltd., Kosaka, Japan), with an accuracy of $0.01 \mathrm{~mm}$, calibrated with a sample length of $0.8 \mathrm{~mm}, 2.4 \mathrm{~mm}$, and $0.5 \mathrm{~mm} / \mathrm{s}$ percussion. Three readings were taken for each specimen and the mean value was obtained. 


\section{Preparation of specimens}

The specimens $(n=60)$ were randomly allocated to the control group (CG, $\mathrm{n}=30$ ) or to the experimental group (LG group, $\mathrm{n}=30$ ), coated with Liquid Glass Shield silicon dioxide (TOPTEK Equipamentos Ltda, Belo Horizonte, Brazil). Each specimen was coated with silicon dioxide according to the manufacturer's instructions. Initially, a vial of silicon dioxide was shaken before each application and sprayed on sterile gauze. The gauze was used to rub the product on the resin surface. ${ }^{16}$ The blocks were stored in a vial for $24 \mathrm{~h}$ at room temperature to remove any solvent interferences and to wait for the curing time.

\section{Scanning electron microscopy (SEM)}

SEM was performed to evaluate the acrylic resin surface after the application of silicon dioxide. One specimen from each group was fixed to a support and coated with gold in an argon atmosphere using a gold module on a vacuum evaporator, according to Jarros et al. ${ }^{18}$ The samples were observed using a Quanta 250 ${ }^{\mathrm{TM}}$ SEM scanning electron microscope (ThermoFisher, Waltham, , USA) at $1000 \times$ magnification.

\section{Contact angle}

Three randomly selected specimens from each group had their surfaces evaluated according to the degree of hydrophobicity. The degree of hydrophobicity ( $\Delta$ Gsws) and surface energy were evaluated using the approach of Van Oss et al., ${ }^{19}$ in which drops of a standardized liquid (water, glycerol, or bromonaphthalene) are placed on the resin surface. The drop generates a surface tension on the resin, and this results in a variable angle of the drop itself, according to surface hydrophobicity. The average angulation of each liquid was analyzed, and the surface energy was calculated. This angle was measured with an optical tensiometer (model OCA 15 PLUS, DATAPHYSICS) equipped with image analysis software (Attension Theta).

Water contact angles were used as a qualitative indication of surface hydrophobicity, with an angle less than $65^{\circ}$ indicating a more hydrophilic surface. ${ }^{20}$
Each test was performed in triplicate and at least 20 contact angles per sample were measured in each of the three standardized liquids.

\section{In situ exposure}

For the in situ study, 20 volunteers (aged 45 to 67 years) were selected according to the following inclusion criteria: normal salivary flow, absence of dental caries and/or periodontal disease, and no antibiotics administered at least 1 month prior to the study. The exclusion criteria included volunteers who were smokers or those wearing orthodontic devices or fixed or removable prostheses. The upper arch of each volunteer was molded with alginate (Jeltrate Dustless, Dentsply - Rio de Janeiro, Brazil) and the plaster models were made of special plaster (Durone IV, Dentsply Indústria e Comércio. Petrópolis, Brazil).

In the plaster models, six cubes of heavy addition silicone (Elite HD +, Zhermack Dental, Rome, Italy) measuring $5 \mathrm{~mm} \times 5 \mathrm{~mm} \times 3 \mathrm{~mm}$ were secured with cyanoacrylate glue (Super bonder: Loctite, Henkel Ltda, São Paulo, Brazil) in order to form spaces for the subsequent insertion of the specimens, facing the oral cavity.

The model set + silicone blocks were waterproofed (Cel-Lac, SS White Goods Dental Ltda., Rio de Janeiro, Brazil) for the manufacture of intraoral palatal devices in self-curing acrylic resin (JET Clássico Artigos Odontológicas Ltda., Campo Limpo Paulista, Brazil).

The acrylic resin palatal devices containing six samples, three from each group $(n=60)$ were used by the volunteers for 2 days. The specimens were fixed onto the palatal devices using sticky wax and were positioned $0.5 \mathrm{~mm}$ below the surface of the device to allow biofilm to accumulate (Figure 1). The volunteers were instructed to wear the device throughout the day, except during meals, while drinking fluids (except water), and during oral hygiene. During these periods, the devices were stored in a container with gauze soaked in distilled water. The volunteers were instructed not to subject the devices to fluoride-containing solutions, and the device should be cleaned only on the inside. On the morning of the 2nd day, the devices were delivered 


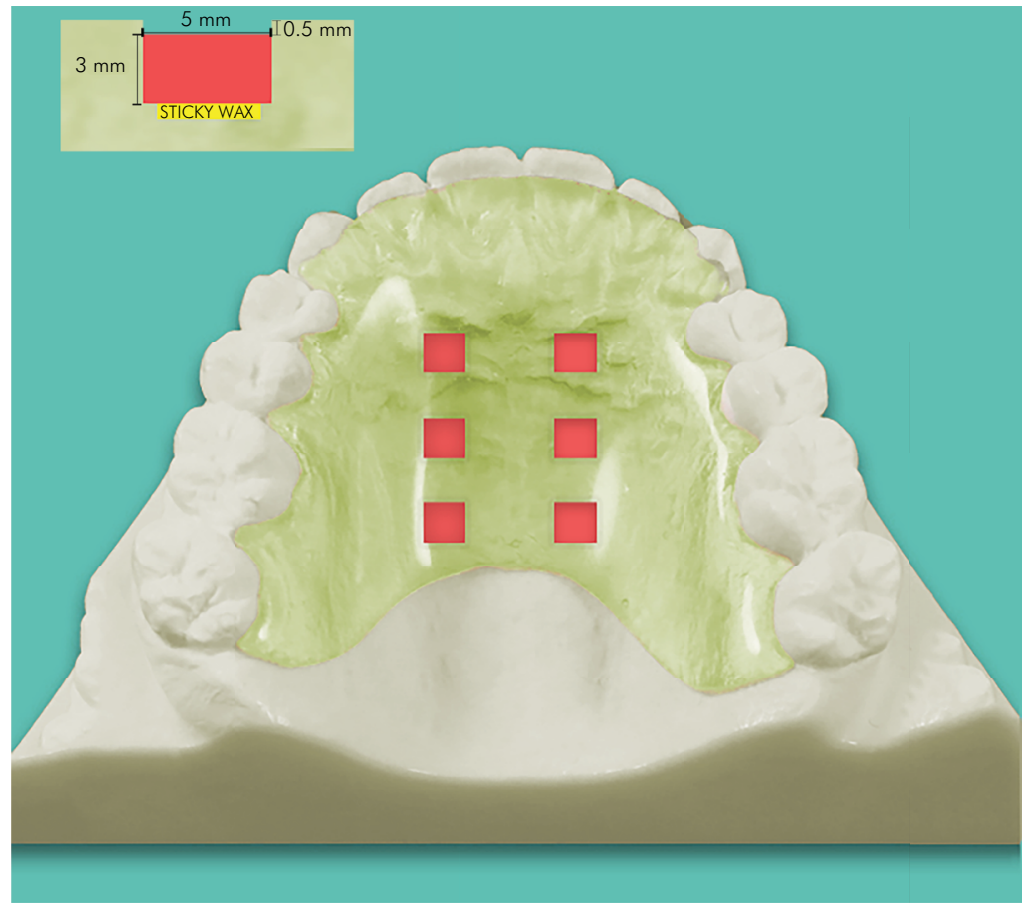

Figure 1. Palatal device with specimens secured with sticky wax.

to the researchers for collection of specimens and quantification of biofilm.

\section{Quantification of polymicrobial biofilm}

The biofilm formed on the acrylic resin blocks by the classic methods for assessing cell viability ${ }^{21}$ and total biomass ${ }^{22}$ was quantified.

\section{Metabolic activity}

2,3-bis (2-methoxy-4-nitro-5-sulfophenyl) -5(phenylamino) -carbonyl-2H-tetrazolium-hydroxide reagent was used to evaluate metabolic activity (quantification and viable cells in the biofilm) (XTT; Sigma-Aldrich, San Luis, USA) according to Negri et al. ${ }^{23}$ and Jarros et al. ${ }^{24}$ Each specimen was removed from the palatal device and placed individually in a well of a 96-well plate. $200 \mu \mathrm{L}$ of final XTT solution was added to each well, incubated for $3 \mathrm{~h}$ at $37^{\circ} \mathrm{C}$, and shaken at $110 \mathrm{rpm}$. The final XTT solution was prepared with $10 \mu \mathrm{g} / \mu \mathrm{L}$ of phenazine methosulfate (PMS) (Sigma-Aldrich, San Luis, USA). Absorbance was then measured on a spectrophotometer (SpectraMax Plus 384, San Luis, USA) at $490 \mathrm{~nm}$. Absorbance values were standardized per unit area of the well (absorbance/ $\mathrm{cm}^{2}$ ). A specimen that did not come into contact with the volunteer was used as negative control. Absorbance values of the negative control wells were subtracted from the values of the test wells to account for any background absorbance. ${ }^{23,24}$

\section{Total biomass}

To assess the total biomass composed of extracellular matrix and cells, the biofilm was fixed with $200 \mu \mathrm{L}$ of $100 \%$ (v/v) methanol for 15 $\mathrm{min}$. The specimens were stained with a $0.1 \% \mathrm{v} / \mathrm{v}$ crystal violet solution (CV; Sigma-Aldrich, San Luis, USA) for $5 \mathrm{~min}$. Subsequently, the specimens were washed twice with sterile Milli-Q water and bleached with acetic acid (33\% v/v). Finally, $100 \mu \mathrm{L}$ of the decolorizing solution for each sample was transferred to a new plate and measured with a spectrophotometer plate reader (SpectraMax Plus 384 microplate reader, San Luis, USA) at $620 \mathrm{~nm}$. Those specimens that did not come into contact with volunteers were used as negative controls. The absorbance values of the negative controls were subtracted from the values of the test wells 
to minimize background interference. The final absorbance values were standardized according to the area (absorbance $/ \mathrm{cm}^{2}$ ).

\section{Statistical analysis}

Preliminary data from the pilot sample were used to calculate sample size. Cohen's distance was used to evaluate effect size. Consequently, an $85 \%$ test power was obtained $(n=19)$, considering a significance level of $5 \%$ and effect size of 0.73 . The data were subjected to Bartlett's test, which indicated lack of normal distribution. The fact that each individual received three replicates of blocks in their mouths suggests inherent variability in each volunteer, which possibly interferes with the response variable, the methodology of generalized mixed models was adopted to accommodate these characteristics and, given that the data presented positive asymmetry, a mixed gamma model was used. This means that the variability of treatments was considered as fixed effects and the inherent or latent variability of each individual was regarded as a random effect. The significance level was set at $5 \%$. The analyses were performed using the $\mathrm{R}$ i386 3.0.2 software. The contact angle results were analyzed using the SPSS version 23.0 (Statistical Package for the Social Sciences). A significance level of $p \leq 0.05$ was adopted. The statistical significance of the

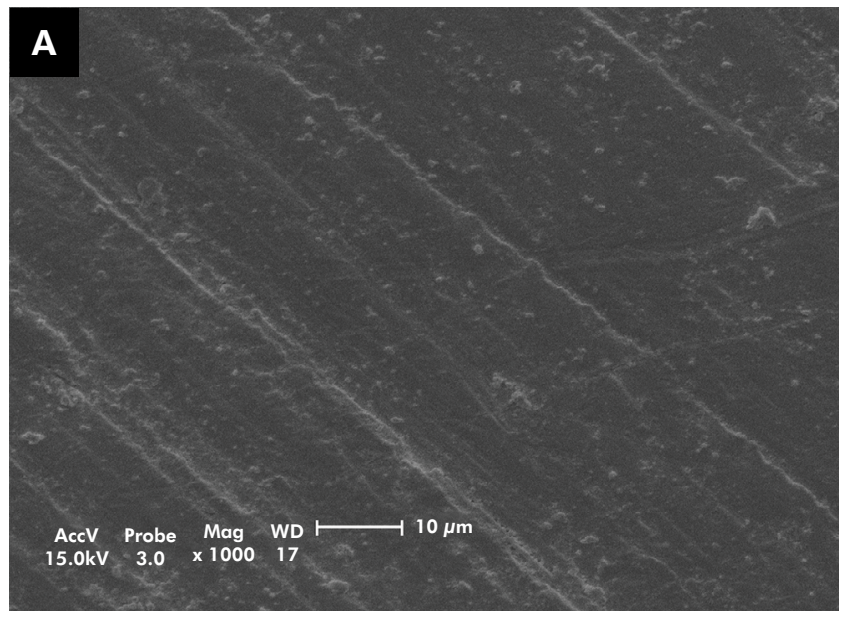

contact angle treated with the silica-coating agent was determined using a Student's t-test.

\section{Results}

Surface roughness $(0.47+0.06 \mu \mathrm{m})$ was presented as suggested by Lima et al..$^{25}$ The photomicrographs obtained by SEM from the surface of the acrylic resin in the CG and from the acrylic resin treated with liquid glass (LG group) are shown in Figure 2.

Although the acrylic resin surface in Figure $2 b$ received liquid glass, this was not noticeable in the SEM as silicon dioxide forms a homogeneous coating layer (approximately $100 \mathrm{~nm}$ ).

The evaluation results for the contact angles (degree) formed between a drop of liquid and the surface of the acrylic resin blocks in both tested groups are shown in Table 1.

Hydrophobicity showed a total $\Delta$ Gsws of -9.5 in the CG and was lower (-54.4) in the LG group, thus demonstrating higher hydrophobicity in the LG $(p<0.05)$. Regarding the ability to donate and receive electrons $(\gamma-(\mathrm{mJm}-2)$ and $\gamma+(\mathrm{mJm}-2)$, there was a change in polarity, in which the CG had lower $\gamma+$ (12.0) and greater $\gamma$ - (14.4), whereas the LG group presented greater $\gamma+(2.1)$ and lower $\gamma$ - (1.6), thus changing the surface from polar to non-polar.

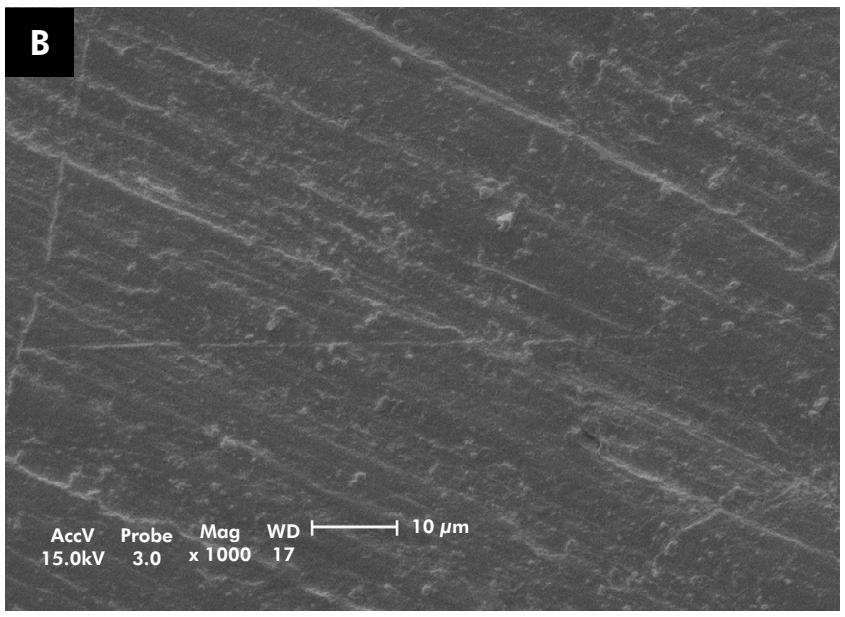

Figure 2. SEM images of acrylic resin block surfaces at $1000 \times$ magnification: (a) non-coated specimen; (b) silicon dioxidecoated specimen. 
Table 1. Water contact angle $(\theta)$, surface tension parameters $(\gamma+, \gamma-)$, and degree of hydrophobicity ( $\triangle \mathrm{Gsws})$ of acrylic resin blocks in the control group (CG) and of those treated with silicon dioxide (LG group). The values are represented by the means \pm standard deviations of three independent experiments for each condition.

\begin{tabular}{ccccc}
\hline \multirow{3}{*}{ Groups } & \multicolumn{4}{c}{ Surface parameters } \\
\cline { 2 - 5 } & $\theta\left(^{\circ}\right)$ & $\gamma^{+}\left(\mathrm{m} J \mathrm{~m}^{-2}\right)$ & $\gamma\left(\mathrm{mJm}^{-2}\right)$ & $\begin{array}{c}\Delta \mathrm{G}_{\text {sws }} \\
\left(\mathrm{mJm}^{-2}\right)\end{array}$ \\
\hline $104.1 \pm 2.8$ & 12.0 & 14.4 & -9.5 \\
& $114.3 \pm 4.4$ & 2.1 & 1.6 & -54.4 \\
\hline
\end{tabular}

The t-test revealed that the coated group (LG) had significantly $(p<0.05)$ lower hydrophobicity than that of the non-coated group (CG).

Table 2. Evaluation of metabolic activity and total biomass of biofilms in the control group (CG) and experimental (LG) group.

\begin{tabular}{|c|c|c|c|}
\hline Test & Group & Mean + SD & $p$-value \\
\hline \multirow{2}{*}{ Metabolic activity } & & $0.44 \pm 0.44$ & \\
\hline & & $0.34 \pm 0.38$ & 0.02 \\
\hline \multirow{2}{*}{ Total biomass } & & $0.73 \pm 0.44$ & \\
\hline & & $0.79 \pm 0.45$ & 0.05 \\
\hline
\end{tabular}

$p$-value: significant when $p<0.05$

The results of the analysis of XTT and CV produced by the microorganisms in the CG and LG group are shown in Table 2.

The metabolic activity of microorganisms in the biofilm formed on the blocks treated with silicon dioxide (LG group) was significantly lower than on the control (CG) blocks ( $p=0.02)$. However, no significant difference $(p=0.05)$ in total biomass was observed.

\section{Discussion}

To the best of our knowledge, this is the first in situ study on the effect of silicon dioxide used as a coating layer on acrylic resin surfaces for the prevention of biofilm adhesion. This study was possible thanks to the good results of a recent in vivo study, which has demonstrated a very high level of tissue biocompatibility of acrylic resin coated with NP-Liquid Glass. ${ }^{17}$

The null hypothesis was accepted once the use of silicon dioxide as a coating layer on acrylic resin inhibited polymicrobial biofilm growth in situ. The blocks of acrylic resin coated with silicon dioxide presented less free energy (CG vs. LG group, -9.5 vs. -54.4) and a greater contact angle (CG vs. LG group, $104.1^{\circ}$ vs. $\left.114.3^{\circ}\right)$. In addition, the metabolic activity of microorganisms in the biofilm (XTT analysis) formed on the blocks treated with silicon dioxide (LG group) was significantly lower than that on the control blocks (CG); however, total biomass (CV analysis) showed no significant differences between the CG and the LG group.

A gamma model was used as the data did not follow a normal distribution. Furthermore, as each patient received three blocks from each group in their mouths, it is reasonable to assume an inherent correlation between them. A Gamma model with random effects on the individual was adopted to accommodate this characteristic.

Previous studies have indicated the need to standardize surface roughness, with averages greater than $0.2 \mu \mathrm{m}$, in order to allow the assessment of the accumulation of microorganisms. ${ }^{25,26}$ The surfaces analyzed in this study had an average of $0.47 \mu \mathrm{m}$. These data are extremely important because they demonstrate standardization of surfaces, thus enabling the adhesion of microorganisms uniformly, reducing the variables that could affect the results.

Surface topography, analyzed by SEM, was similar in both groups, even at $1000 \times$ magnifications. Silicon dioxide forms a thin and homogeneous layer on the entire surface without changing the visual characteristics of the acrylic resin, which represents a great advantage of the product applied. This may have occurred because, in the present study, only one thin layer of silicon dioxide was applied on the acrylic specimens, as suggested by the manufacturer. In the SEM images of coated specimens presented by Azuma et al. ${ }^{14}$ (500× magnification), several different particles were detected and surface roughness decreased compared to non-coated specimens. Furthermore, in the coated group, surface roughness decreased in SEM images and Si was consistently detected in the EDS analysis. In their study, the coating agent was applied three times on the surface of acrylic resin blocks, whereas in the present study it was applied only once. 
Even though SEM images showed no differences between the CG and LG group, the contact angle test revealed that those surfaces coated with silicon dioxide exhibited greater hydrophobicity than the non-coated surfaces. These results have also been demonstrated in previous studies. ${ }^{14,15}$

The Van Oss ${ }^{19}$ methodology was used in this research with the purpose of evaluating the contact angle or wetting angle of each surface, thus providing results that would allow analyzing the wettability of each surface. In this methodology, previously standardized drops of different liquids were applied on the analyzed surfaces. The average of each liquid was calculated and, based on that information, surface energy was determined. In both groups, the surfaces appeared to be hydrophobic $\left(90^{\circ}<\theta<180^{\circ}\right)$ when the drops of water and glycerol were analyzed. As for the drops of bromonaphthalene, the surfaces showed greater wettability with an average angle of $48.3^{\circ}$ in the CG and $64.7^{\circ}$ in the LG group.

A surface with a smaller contact angle has more free energy and is therefore more hydrophobic. On surfaces with freer energy, the liquid interacts with the substrate through chemical bonds, while on surfaces with less free energy the interaction occurs by binding forces. Chemical bonds are stronger than binding forces, which makes freer energy more hydrophilic than less free energy. ${ }^{27}$ On surfaces with high contact energy, the liquid spreads more, creating a smaller contact angle. The calculation of free energy showed the LG group had less free energy $\left(\Delta \mathrm{G}_{|w|=}=-54.4\right)$ than the $C G\left(\Delta G_{|w|=}=-9.5\right)$. These results are extremely important as they allow verifying that silicon dioxide is on the surface and causes changes in it as these changes were not noticeable in the photomicrographs, and indicates that the surfaces treated with silicon dioxide were more hydrophobic than those in the control group, which may hinder microbial adhesion. As for the change in polarity, which is a relationship between the ability to donate and receive electrons $(\gamma-(\mathrm{mJm}-2)$ and $\gamma+(\mathrm{mJm}-2))$ from the surface, the results presented in this study are directly related to the low biofilm formation on the surface. Microbial adhesion can be considered the first stage of biofilm formation on abiotic surfaces, and the change in free energy, which altered the polarity of the evaluated surface, resulting in its repulsion, can have a direct impact on the formation of polymicrobial biofilm. ${ }^{28,29}$

The resin treated with silicon dioxide in the in situ experiments showed significantly lower cell activity, i.e., fewer adhered microorganisms, compared to the CG. The principle of the XTT reduction technique lies in the ability of active cells to metabolize the tetrazolium salt, making them colored compounds, thereby indicating the viability of microbial biofilm metabolism. ${ }^{30,31}$ For the analysis of total biomass with CV dye, the CG showed no statistical difference in total biomass between the materials (treated and untreated). The CV method is widely used to detect total biomass of mono and polymicrobial biofilms, quantifying all the structures that make up the biofilm (polysaccharide matrix and microorganisms). ${ }^{23}$ Accordingly, it can be inferred that there is a smaller number of microorganisms attached to the treated surface (XTT technique), but the same amount of total biomass (CV technique). It is important to note that both tests used in this research are widely used to evaluate different microbial biofilms. ${ }^{32}$ However, one bias that should be mentioned in the $\mathrm{CV}$ technique is the inability to define the biofilm mass of dead or living cells, given that $\mathrm{CV}$ can stain both. ${ }^{33,34}$ Therefore, any results must be correlatable to XTT. In addition, it was not possible to specify which microorganisms were present in the biofilm and its structure.

Note that the limitations of the techniques were minimized with correlations between the methods that complemented each other and allowed us to make a critical and effective analysis. Although in situ studies often have a greater number of variables, in this research it was possible to reduce them by carefully selecting the volunteers, standardizing resins, carrying out the experiments in triplicate, and using the gamma statistical model, which was adopted to account for the random characteristics, inherent in a study carried out with volunteers.

Wady et al. ${ }^{35}$ used an XTT assay to assess Candida albicans adhesion and biofilm formation in dentures made with acrylic resin incorporated with silver nanoparticles. In that in vitro study, the hydrophobicity of the surface was evaluated using the contact angle technique, and the formation and adherence of microorganisms was assessed by the XTT test. The researchers were able to 
notice a reduction in hydrophobicity and no effect on fungal and microbial formation.

It is known that the main microorganism that adheres to the surface of resin-based prostheses is Candida albicans. It has been demonstrated in a previous in vitro study that silicon dioxide coating on acrylic resin was able to reduce the adhesion of Candida albicans to prostheses. ${ }^{16}$

As the objective of the present study was to evaluate whether silicon dioxide can inhibit the formation of microbial biofilm, only the total microbial load was evaluated, without the identification of microorganisms. It would be interesting to know which microorganisms were identified in the tested specimens and which microorganisms in the group treated with silicon dioxide showed significantly lower cell activity than the control. This was not performed and is a limitation of this study. Unlike an in vitro study, in which growth conditions and the type of microorganisms are fully controllable, in an in vivo study with volunteers, the load and type of microbiota of each individual is more difficult to control. If volunteers without the presence of Candida spp. as microbiota had been used as an exclusion criterion, the number of volunteers would have been reduced.

Nevertheless, acrylic resins coated with silicon dioxide showed remarkable advantages over the resins with a conventional surface, regarding the activity of polymicrobial biofilm. These results may have implications of great clinical importance, as silicon dioxide is inexpensive and easy to apply. The present study based on 20 volunteers is just a first step in assessing the possible clinical differences in volunteers wearing conventional prostheses and the resins proposed in this work; however, it is an important study considering the clinical potential of its applications.

Future studies on the duration of silicon dioxide coating on acrylic resin surface and its resistance to brushing are recommended to elucidate the average time for reapplication of the coating.

\section{Conclusions}

The application of a silicon dioxide coating layer on thermally activated acrylic resin has been shown to reduce the activity of polymicrobial biofilm formed in situ. This procedure can be advantageous for patients with conventional complete dentures or on protocols for implants made of acrylic resin and who have motor difficulties in cleaning them.

\section{Acknowledgments}

This study was supported by Coordenação de Aperfeiçoamento de Pessoal de Nível Superior - Brasil (CAPES) - Finance Code 001, Conselho Nacional de Desenvolvimento Científico e Tecnológico (CNPq) $n^{\circ}$ 421620/2018-8, Fundação de Amparo à Pesquisa do Estado do Paraná (Fundação Araucária), and Financiadora de Estudos e Projetos (FINEP/COMCAP).

\section{References}

1. Ministerio da Saúde (BR). SB BRAZIL 2010: Pesquisa Nacional de Saúde Bucal: resultados principais. Brasilia, DF; 2012 [cited year Month day]. Available from: https://bvsms.saude.gov.br/bvs/publicacoes/pesquisa_nacional_saude_bucal.pdf

2. Carvalho JC, Schiffner U. Dental caries in european adults and senior citizens 1996-2016: ORCA Saturday Afternoon Symposium in Greifswald, Germany - Part II. Caries Res. 2019;53(3):242-52. https://doi.org/10.1159/000492676

3. Anne G, Oliganti SHB, Ata J, Budati S, Manne P, Chiramana S. The effect of aluminum oxide addition on the flexural strength of heat activated acrylic resin: an in vitro study. J Dr NTR Univ Health Sci. 2015;4(1):21-3. https://doi.org/10.4103/2277-8632.153307

4. Straioto FG, Ricomini Filho AP, Fernandes Neto AJ, Del Bel Cury AA. Polytetrafluorethylene added to acrylic resins: mechanical properties. Braz Dent J. 2010 Jan;21(1):55-9. https://doi.org/10.1590/S0103-64402010000100009

5. Cunha TR, Regis RR, Bonatti MR, Souza RF. Influence of incorporation of fluoroalkyl methacrylates on roughness and flexural strength of a denture base acrylic resin. J Appl Oral Sci. 2009 Mar-Apr;17(2):103-7. https://doi.org/10.1590/S1678-77572009000200006

6. Altieri KT, Sanita PV, Machado AL, Giampaolo ET, Pavarina AC, Jorge JH, et al. Eradication of a mature methicillinresistant Staphylococcus aureus (MRSA) biofilm from acrylic surfaces. Braz Dent J. 2013 Sep-Oct;24(5):487-91. https://doi.org/10.1590/0103-6440201302289 
Silva RVDR, Jarros IC, Del Bel Cury AA, Sidhy SK, Silva S, Negri MFN, et al.

7. Pinto TM, Neves AC, Leao MV, Jorge AO. Vinegar as an antimicrobial agent for control of Candida spp. in complete denture wearers. J Appl Oral Sci. 2008 Nov-Dec;16(6):385-90. https://doi.org/10.1590/S1678-77572008000600006

8. Peracini A, Davi LR, Ribeiro NQ, Souza RF, Silva CHL, Paranhos HFO. Effect of denture cleansers on physical properties of heat-polymerized acrylic resin. J Prosthodont Res. 2010 Apr;54(2):78-83. https://doi.org/10.1016/i.jpor.2009.11.004

9. Casemiro LA, Martins CHG, Pires-de-Souza FC, Panzeri H. Antimicrobial and mechanical properties of acrylic resins with incorporated silver-zinc zeolite - part I. Gerodontology. 2008 Sep;25(3):187-94. https://doi.org/10.1111/j.1741-2358.2007.00198.x

10. Lefebvre CA, Wataha JC, Cibirka RM, Schuster GS, Parr GR. Effects of triclosan on the cytotoxicity and fungal growth on a soft denture liner. J Prosthet Dent. 2001 Apr;85(4):352-6. https://doi.org/10.1067/mpr.2001.115249

11. Santos RL, Pithon MM. Carvalho FG., Ramos AAS., Romanos MTV, Santos RL, et al. Mechanical and biological properties of acrylic resins manipulated and polished by different methods. Braz Dent J. 2013 Sep-Oct 2013;24(5):492-7. https://doi.org/10.1590/0103-6440201302293

12. Jurgens R, Schwindt S, inventors. Anitbakterielle coating composition based on a silica-generating agent, a set of applications, a nanoscale coating the preparation of the coating, further processing of the coating as well as their use. Google Patents, Germany DE102006008535A1. 2007 Aug 30.

13. Mogensen JE, Jorgensen PE, Thomsen TR. A microbiological evaluation of SiO2 -coated textiles in hospital interiors: the effect of passive coatings on the cleaning potential of interior textiles. J Ind Text. 2016;46(2):361-71. https://doi.org/10.1177/1528083715580543

14. Azuma A, Akiba N, Minakuchi S. Hydrophilic surface modification of acrylic denture base material by silica coating and its influence on Candida albicans adherence. J Med Dent Sci. 2012 Mar;59(1):1-7. https://doi.org/10.11480/imds.590101

15. Yodmongkol S, Chantarachindawong R, Thaweboon S, Thaweboon B, Amornsakchai T, Srikhirin T. The effects of silane-SiO2 nanocomposite films on Candida albicans adhesion and the surface and physical properties of acrylic resin denture base material. J Prosthet Dent. 2014 Dec;112(6):1530-8. https://doi.org/10.1016/i.prosdent.2014.06.019

16. Silva RV, Costa MI, Jarros IC, Del Bel Cury AA, Sidhu SK, Negri M, et al. Effect of Silicon dioxide coating of acrylic resin surfaces on Candida albicans adhesion. Braz Oral Res. 2020;34:e110. https://doi.org/10.1590/1807-3107bor-2020.vol34.0110

17. Lacerda-Santos R, Lima AB, Penha ES, Santos A, Carvalho FG, Pithon MM, et al. In vivo of silicon dioxide nanofilm used as antimicrobial agent on acrylic surface. An Acad Bras Cienc. 2020 Apr 17;92(1):e20181120. https://doi.org/10.1590/0001-3765202020181120

18. Jarros IC, Okuno E, Costa MI, Veiga FF, Bonfim-Mendonca PS, Negri MF, et al. Yeasts from skin colonization are able to cross the acellular dermal matrix. Microb Pathog. 2018 Apr;117:1-6. https://doi.org/10.1016/i.micpath.2018.02.014

19. Van Oss CJ, Ju L, Chaudhury MK, Good RJ. Estimation of the polar parameters of the surface tension of liquids by contact angle measurements on gels. J Colloid Interface Sci. 1989;128(2):313-9. https://doi.org/10.1016/0021-9797(89)90345-7.

20. Vogler EA. Structure and reactivity of water at biomaterial surfaces. Adv Colloid Interface Sci. 1998 Feb;74(1-3):69-117. https://doi.org/10.1016/S0001-8686(97)00040-7

21. Pierce CG, Uppuluri P, Tummala S, Lopez-Ribot JL. A 96 well microtiter plate based method for monitoring formation and antifungal susceptibility testing of Candida albicans biofilms. J Vis Exp. 2010 Oct;21(44):2287. https://doi.org/ 10.3791/2287

22. O'Toole GA. Microtiter dish biofilm formation assay. J Vis Exp. 2011 Jan;30(47):2437. https://doi.org/10.3791/2437

23. Negri M, Silva S, Capoci IR, Azeredo J, Henriques M. Candida tropicalis biofilms: biomass, metabolic activity and secreted aspartyl proteinase production. Mycopathologia. 2016 Apr;181(3-4):217-24. https://doi.org/10.1007/s11046-015-9964-4

24. Jarros IC, Veiga FF, Correa J., Barros I, Gadelha MC, Voidaleski MF, et al. Microbiological and virulence aspects of Rhodotorula mucilaginosa. EXCLI J. 2020 May 27;19:687-704. https://doi.org/10.17179/excli2019-1672

25. Lima EM, Moura JS, Del Bel Cury AA, Garcia RC, Cury JA. Effect of enzymatic and NaOCl treatments on acrylic roughness and on biofilm accumulation. J Oral Rehabil. 2006 May;33(5):356-62. https://doi.org/10.1111/i.1365-2842.2005.01564.x

26. Bollen CM, Lambrechts P, Quirynen M. Comparison of surface roughness of oral hard materials to the threshold surface roughness for bacterial plaque retention: a review of the literature. Dent Mater. 1997 Jul;13(4):258-69. https://doi.org/10.1016/S0109-5641(97)80038-3

27. Gennes PG. Wetting: statics and dynamics. Rev Mod Phys. 1985;57(3):827-63. https://doi.org/10.1103/RevModPhys.57.827

28. Agarwalla SV, Ellepola K, Costa MC, Fechine GJ, Morin JL, Castro Neto AH, et al. Hydrophobicity of graphene as a driving force for inhibiting biofilm formation of pathogenic bacteria and fungi. Dent Mater. 2019 Mar;35(3):403-13. https://doi.org/10.1016/i.dental.2018.09.016

29. Kusuma Yulianto HD, Rinastiti M, Cune MS, de Haan-Visser W, Atema-Smit J, Busscher HJ, et al. Biofilm composition and composite degradation during intra-oral wear. Dent Mater. 2019 May;35(5):740-50. https://doi.org/10.1016/i.dental.2019.02.024

30. Pierce CG, Uppuluri P, Tristan AR, Wormley FL Jr, Mowat E, Ramage G, et al. A simple and reproducible 96 -well plate-based method for the formation of fungal biofilms and its application to antifungal susceptibility testing. Nat Protoc. 2008;3(9):1494-500. https://doi.org/10.1038/nprot.2008.141

31. Koban I, Matthes R, Hubner NO, Welk A, Sietmann R, Lademann J, et al. XTT assay of ex vivo saliva biofilms to test antimicrobial influences. GMS Krankenhhyg Interdiszip. 2012;7(1):Doc06. https://doi.org/10.3205/dgkh000190 
Evaluation of biofilm formation on acrylic resin surfaces coated with silicon dioxide: an in situ study

32. Monteiro DR, Silva S, Negri M, Gorup LF, Camargo ER, Oliveira R, et al. Silver nanoparticles: influence of stabilizing agent and diameter on antifungal activity against Candida albicans and Candida glabrata biofilms. Lett Appl Microbiol. 2012 May;54(5):383-91. https://doi.org/10.1111/j.1472-765X.2012.03219.x

33. Stepanovic S, Vukovic D, Hola V, Di Bonaventura G, Diukic S, Cirkovic I, et al. Quantification of biofilm in microtiter plates: overview of testing conditions and practical recommendations for assessment of biofilm production by staphylococci. Acta Pathol Microbiol Scand Suppl. 2007 Aug;115(8):891-9. https://doi.org/10.1111/j.1600-0463.2007.apm_630.x

34. Pantanella F, Valenti P, Natalizi T, Passeri D, Berlutti F. Analytical techniques to study microbial biofilm on abiotic surfaces: pros and cons of the main techniques currently in use. Ann Ig. 2013 Jan-Feb;25(1):31-42. https://doi.org/10.7416/ai.2013.1904

35. Wady AF, Machado AL, Zucolotto V, Zamperini CA, Berni E, Vergani CE. Evaluation of Candida albicans adhesion and biofilm formation on a denture base acrylic resin containing silver nanoparticles. J Appl Microbiol. 2012 Jun;112(6):1163-72. https://doi.org/10.1111/j.1365-2672.2012.05293.x 